\title{
Evaluation of mechanical properties of friction stir welded commercially pure aluminium
}

\author{
S. Suresh Kumar ${ }^{1 *}$, B. Ravisankar ${ }^{2}$, Vishnu Chandar. S ${ }^{1}$, R.P. Dhivakar Raviram ${ }^{1}$ \\ ${ }^{1}$ Department of Mechanical Engineering, Saveetha School of Engineering, Saveetha Institute of Medical and Technical Sciences, \\ Chennai - 602105, India. \\ ${ }^{2}$ Department of Metallurgical and Materials Science Engineering, National Institute of Technology, Tiruchirappalli 620 015, India.
}

\begin{abstract}
In this study, friction stir welding (FSW) of commercially pure aluminium is carried out. The main defects existing in this process are cavity, irregular material flow due to unsuitable selection of welding parameters. In this study, to reduce the defects by selecting suitable parameter and welding quality determined by mechanical testing methods and non-destructive testing methods. Welding is done with preheating the base metals and without preheating the base metals and their effects are analyzed with similar parameter. The parameters considered for this work are spindle rotational speed (rpm), tool travel speed $(\mathrm{mm} / \mathrm{min})$ and axial force $(\mathrm{kN})$. The experimental results are evaluated by Destructive Test and Nondestructive test methods. The characterization study is performed by Optical microscope and Scanning Electron microscopy (SEM).
\end{abstract}

Keywords. Friction Stir Welding, Destructive Test (DT), Non-Destructive Test (NDT)

\section{Introduction}

Friction stir welding (FSW) is a new welding process found by the Welding Institute in 1991. The weld zone not melted but it becomes softened by forms a sound weld nugget under the tool's pressure. This joining procedure cannot be used and difficult to weld by conventional joining methods [1-3]. The following test was conducted on the welded samples such as tensile test, metallographic evaluation, micro hardness and impact test. The result of tensile strength of welded zone is directly proportional to the welding speed [4-5]. Hardness value was observed in the weld region, it was less comparing parent metal [6]. The Welded zone was observed through the optical microscope, this is fine strengthening precipitates due to the formation of fine equiaxed grains and uniformly distributed in the weld region [7]

Most of the researcher evaluated in similar and dissimilar aluminum alloy welded by friction stir and determined its strength by tensile test, bend Test, impact strength and hardness survey across the friction stir welded area and characterized by optical microscope, Scanning Electron Microscope and XRD[8-9].
The Ultimate aim of this study friction stir welding operations is to be select the suitable welding process conditions such as rotational speed, welding speed and axial force applied on the preheat treated, non- preheat treated and both set of combination of materials for aluminium 1100 welded and predicted the weld soundness of the above combination using destructive and non-destructive testing methods.

\section{Experimental procedure}

The commercially pure aluminium of grade namely 1100 used for this study. The Welding of Al 1100 is carried out in three conditions. In the first condition metal is preheated to $300^{\circ} \mathrm{C}$ and then welding process is carried out. In the second condition preheating is neglected. The third condition is both (preheated and non-preheated) combination of the above process. The dimension of aluminium plate is $50 \mathrm{~mm}$ wide, $100 \mathrm{~mm}$ long and thickness is $6 \mathrm{~mm}$. The schematic friction stir welding process shown in Fig.1. The chemical composition of parent metal is shown in Table. 1

Table 1 Chemical Compositions of the Base Metal

\begin{tabular}{|c|c|c|c|c|c|c|}
\hline Element & $\mathrm{Si}$ & $\mathrm{Fe}$ & $\mathrm{Cu}$ & $\mathrm{Mn}$ & $\mathrm{Zn}$ & $\mathrm{Al}$ \\
\hline $\mathrm{Wt} \%$ & 0.42 & 0.34 & 0.08 & 0.02 & 0.025 & Balance \\
\hline
\end{tabular}

The tool material used for this study is High-chromium high-carbon steel. The diameter of the pin is $6 \mathrm{~mm}$ and height of the pin is $5.7 \mathrm{~mm}$. The diameter of shoulder is $15 \mathrm{~mm}$.(Fig.2.) Al 1100 samples welded by FSW is

\footnotetext{
Corresponding author: ssureshrec@gmail.com
} 
shown in fig. 3 and the welding process parameters are listed in the Table. 2

Once the welding is completed the welded samples first tested under the non-destructive testing after that samples were cut through EDM for destructive testing methods. The microstructure samples surface polished and ultra-cleaned from different grade emery papers, disc polishing and finally cleaned by ultrasonic both using acetone. The samples were etched by $20 \mathrm{ml} \mathrm{HCl}$, $20 \mathrm{ml} \mathrm{HF}, 10 \mathrm{ml} \mathrm{H}_{2} \mathrm{SO}_{4}$ and $50 \%$ of water. The scanning electron microscope micrographs taken on the well ultrapolished samples of three conditions of welded samples. The specimen impact strength is tested by using Impact Tester (Model IT-30) as well as the tensile strength determined by tensile testing machine (Model - TKG). The SEM analysis taken from JEOL JSM-6460. The optical micrograph analysed by Olympus BX53M.

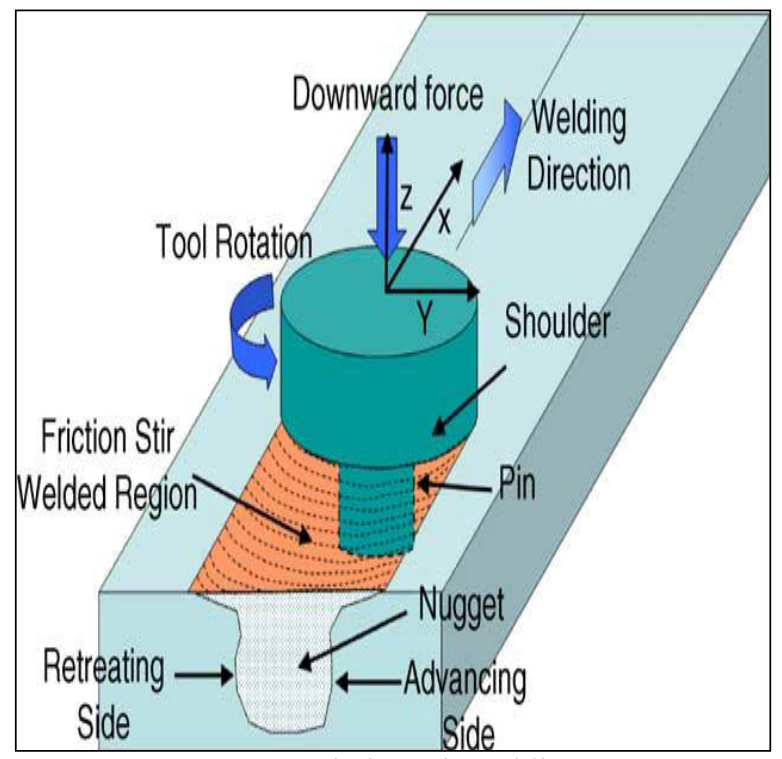

Fig.1. Friction stir welding

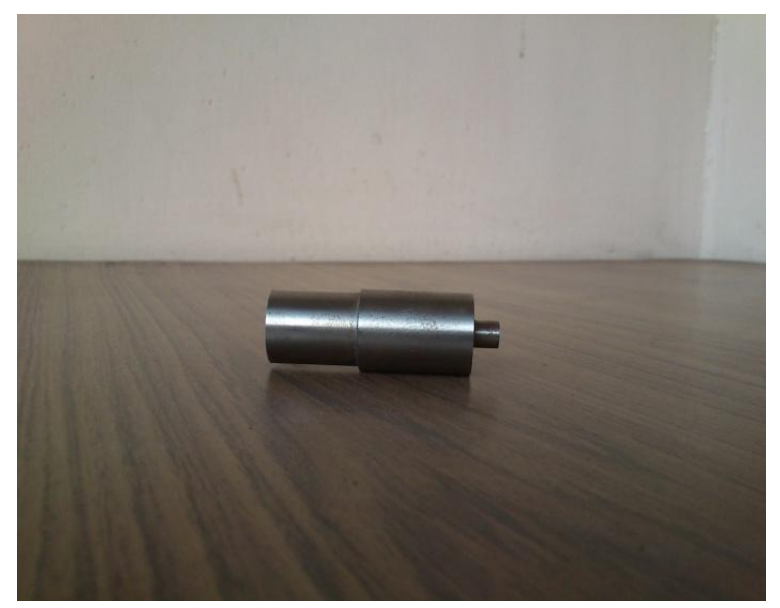

Fig 2 High-chromium high-carbon tool steels

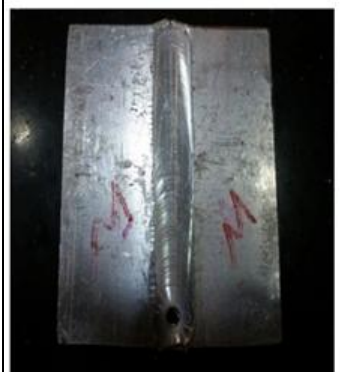

(a)

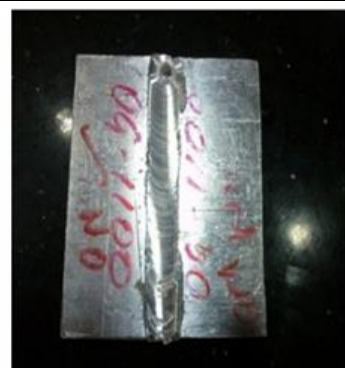

(b)

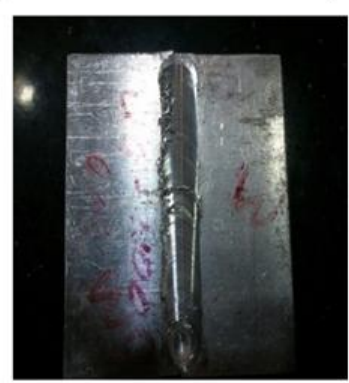

(c)

Fig .3. (a) Preheated, (b) Non-preheated, (c) Preheated and non-preheated welded Joints

Table. 2 Process parameters for friction stir welding

\begin{tabular}{|l|c|c|c|}
\hline $\begin{array}{l}\text { Process } \\
\text { parameters }\end{array}$ & AL1100 & AL1100 & AL1100 \\
WOH-WHO & WH-WOH \\
\hline $\begin{array}{l}\text { Tool rotation } \\
\text { speed (rpm) }\end{array}$ & 400 & 400 & 400 \\
\hline $\begin{array}{l}\text { Welding } \\
\text { speed } \\
\text { (mm/min) }\end{array}$ & 60 & 60 & 60 \\
\hline $\begin{array}{l}\text { Axial } \\
\text { load(KN) }\end{array}$ & 10 & 10 & 10 \\
\hline
\end{tabular}

\section{Results and discussion}

The following tests are conducted on the welded samples after welding to confirm the quality of the welded joint and the material flow.

\subsection{Hardness test result}

The hardness survey carried out using Rockwell hardness tester. Specimens welded with Preheated achieves hardness is $92 \mathrm{HRB}$, specimens welded non Preheated obtain hardness of $86 \mathrm{HRB}$, either specimen non preheated - preheated obtains hardness of 88 HRB.

\subsection{Impact test result}

Similar specimens welded Preheated obtains impact value of 26J, specimens welded non Preheated obtains impact value of $21 \mathrm{~J}$, either specimen non preheated preheated obtains value of $23 \mathrm{~J}$.

\subsection{Tensile test result}

The specimens welded Preheated obtains tensile strength of $114 \mathrm{MPa}$, specimens welded non preheated 
obtains strength of $92 \mathrm{MPa}$, either specimen non preheated - preheated obtains tensile strength of $98 \mathrm{MPa}$.

\subsection{Microstructure results}
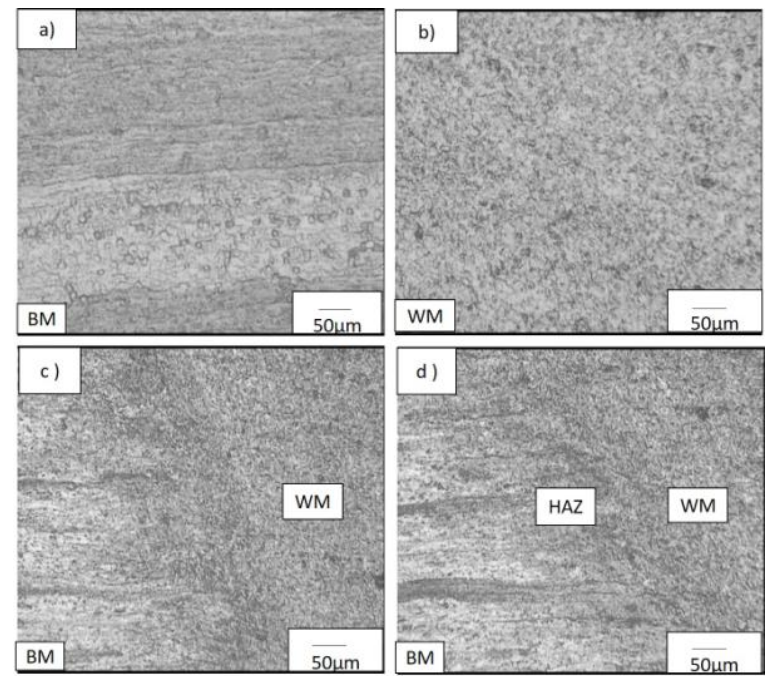

Fig.4 The micrographs of preheated (a) BM base metal, (b) WM weld metal, (c) Weld metal and parent metal,

(d) Heat affected zone (HAZ)

Fig.4 shows preheated aluminium 1100 samples microstructure. The base material (BM) zone, welded zone (WM) and heat affected zones (HAZ) are well defined in all the microstructures (Fig.4,5 and 6). Grain growths were obtained comparing the non-preheated sample(Fig.5). However, the Fig. 6 shows preheated and non-preheated samples microstructures. The welded paths were not in uniform material distribution was noted in welded zone because of one plate is preheated another one is non preheated.
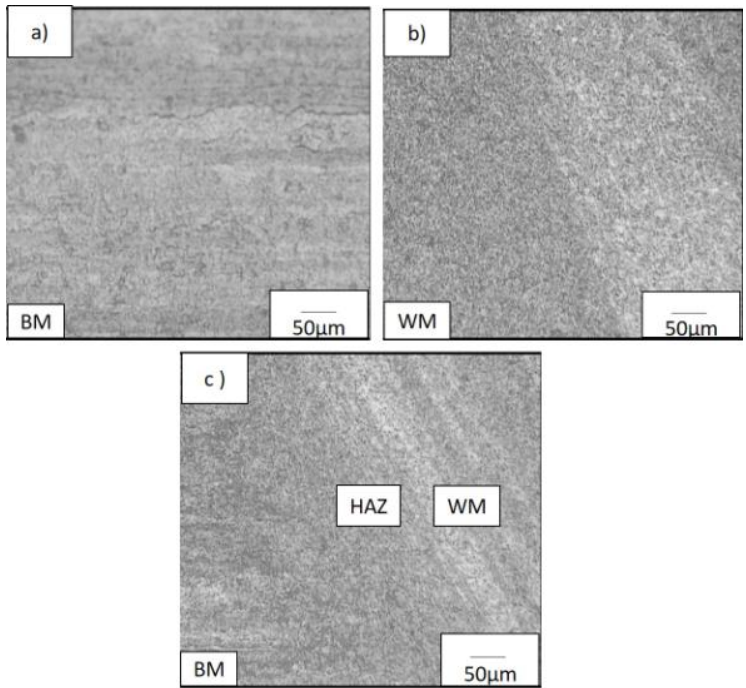

Fig.5.The micrographs of aluminium alloy Non Preheated (a) base metal, (b) weld metal,

(c) Heat affected zone
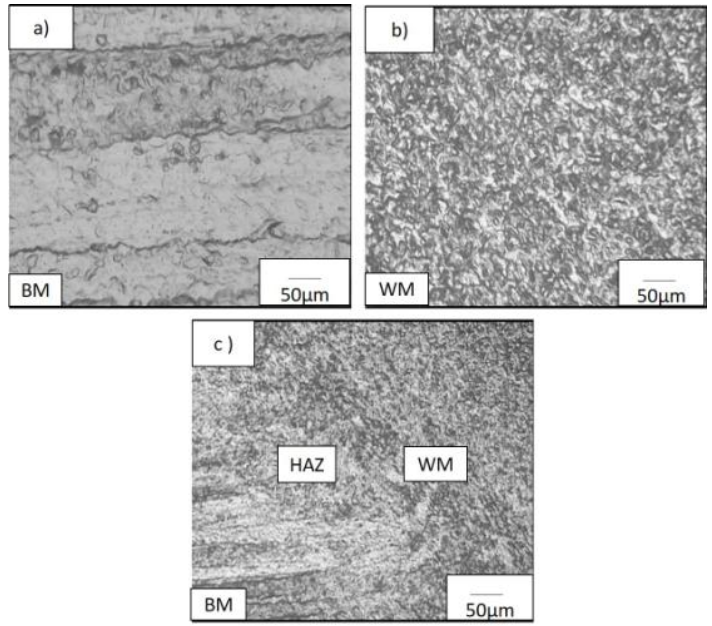

Fig.6. The micrographs of aluminium alloy preheated and non-preheated (a) base metal, (b) weld metal,

(c) heat affected zone

\subsection{Ultrasonic test}

It is one of the non-destructive method, it is suitable method of detect the flaw of the FSW process. It is having various displays scanning format. In commonly three scanning method used in ultrasonic testing method. The scanning method is called A-scan, B-scan and Cscan. Each and every scan displays having own its properties. In this study A-scan display method used.

\subsubsection{A-Scan}

The A-scan presentation displays the form of sound echos. The ultrasound energy or wave fall down on the test samples, the amount of sound echos received from the welded samples determind by the quality of the weld. The range setting $(50 \mathrm{~mm})$ set by the thickness of the materials. The thickness of the welded samples is $6 \mathrm{~mm}$, hence the eight multiple reflected echo signals gets from the test samples with attenuation. It means the welded sample has without flaws and proved the quality of the weld. In other hand, any flaws are presented in the test sample the multiple echos not presented. It confirmed that the FSW process parameter is predicted in given three conditions.

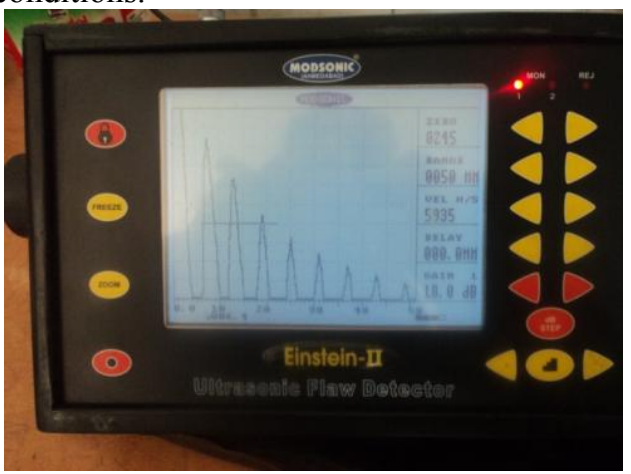

Fig.7. Ultrasonic test result for preheated and nonPreheated welded joints

Range for the welded joint is $50 \mathrm{~mm}$ for the specimen $6 \mathrm{~mm}$ thickness. Eight echoes had been noted for all the joint and all the joints are defect free (Fig.7). 


\subsection{Radiographic testing}

Radiography testing is the one of the classical inspection methods based on the differential density of penetrating radiation of electromagnetic radiation of very short wavelength used to inspect the test samples. this testing method. In this method, over all advantage of other nondestructive methods it means in this method having permanent recording medium (Radiography Film). In this method, the quality of the friction stir welded samples determined by radiation absorption from the welded samples. There is no flaws are observed. In this method proved the ultrasonic testing method results of given three samples conditions. From the radiographic testing it has been confirmed all the joints are defect free.

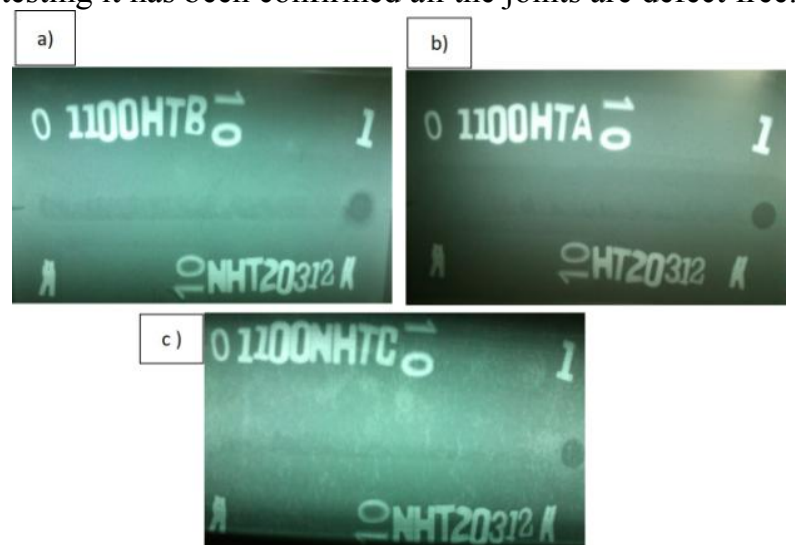

Fig.8. (a) Preheated - Non preheated, (b)Preheated Preheated, (c) Non preheated - non Preheated.

\subsection{SEM analysis}

SEM micrograph of welded zone of preheated, nonpreheated and preheated - non preheated samples shows in Fig. 9, 10 and 11 respectively the following friction stir welding process parameters such as tool rotational speed $400(\mathrm{rpm})$, tool travel speed $60(\mathrm{~mm} / \mathrm{min})$ and axial load $10(\mathrm{KN})$. SEM results are also reflected in optical microscope results. The microstructures show with elongated and cluster fine grains is observed in this zone. It means the preheated and non-preheated (Fig.11) samples welding path was not uniformed comparing other two welding plates.

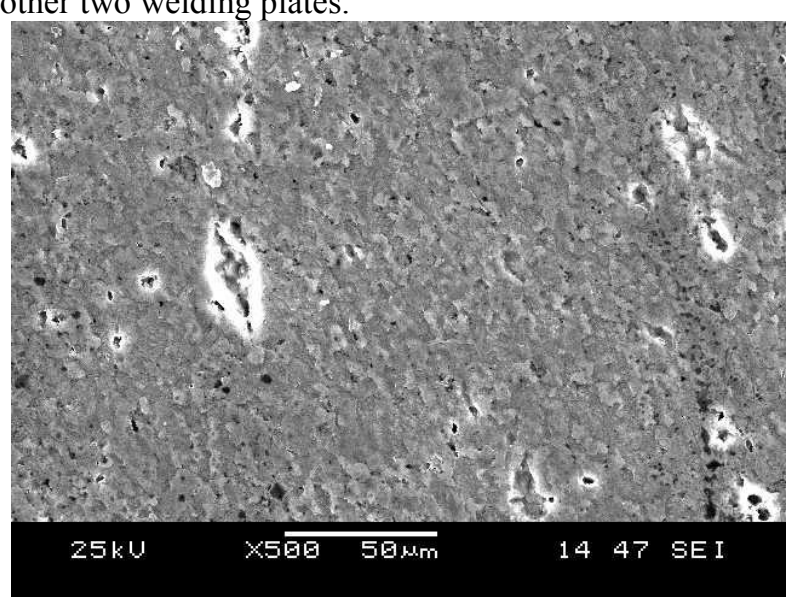

Fig.9. SEM image of welded Area Preheated AL 1100

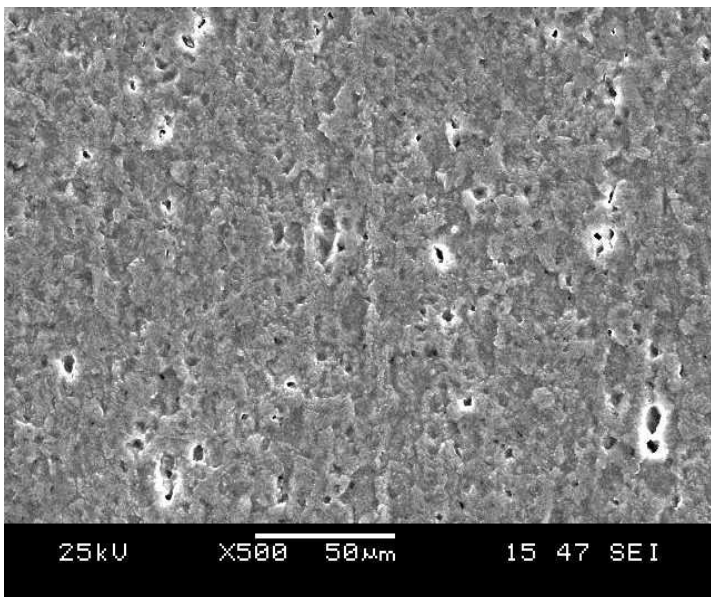

Fig. 10. SEM image of welded Area Non Preheated

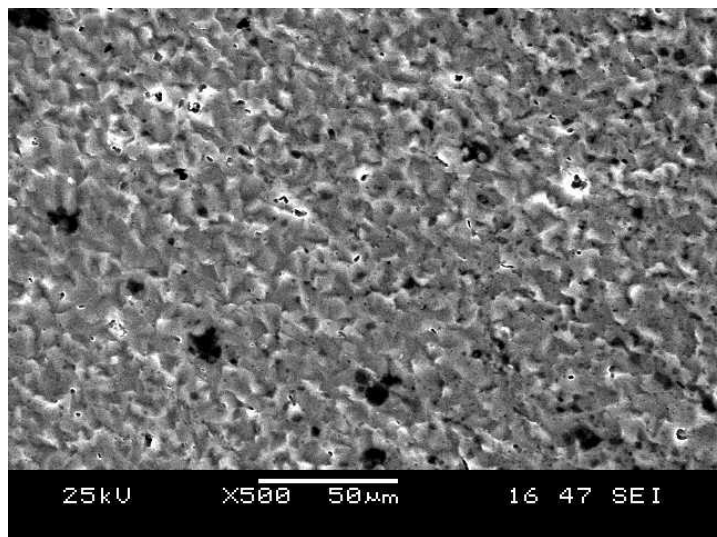

Fig.11. SEM image of welded Area Preheated and Non Preheated

\section{Conclusions}

The main observations of this experimental work summarised as below:

1. The effect of preheating plate strength is good comparing to the others plates, it is determined by destructive tests.

2. The FSW joints have no defects it passes ultrasonic and radiographic test. Hence the friction stir welding parameters is predicted.

3. There is no contamination due to tool in welded zone. It is proved by micro structures analysis.

\section{References}

1. J. Kandasamy, Journal of Materials Manufacturing Processes, 27, (2012).

2. Fu Zhi-hong He, Di-qiu Wang Hong, J. Materials Sci. E, 19, 61-64 (2004).

3. A.Heidarzadeh, H. Khodaverdizadeh, A.Mahmoudi, E. Nazari, Journal of Materials \& Design, 37, 166173 (2012).

4. P. Rao, Journal of Materials Science \& Technology, 28, 414-426 (2011).

5. M. Koilraj, V. Sundareswaran, S. Vijayan, S.R.K. Rao, Materials and Design, 42, 1-7 (2012).

6. G. Padmanaban, V. Balasubramanian, Materials and Design, 30, 2647-2656 (2009). 
7. S.Ramesh Babu,,V.S. Senthilkumar, G. Madhusudhan Reddy, L. Karunamoorthy, Procedia Engineering, 38, 2956-2966 (2012).

8. P. Sadeesh, M. Venkatesh Kannan, V. Rajkumar, P. Avinash, N. Arivazhagan, K. Devendranath Ramkumar, Narayanan, Procedia Engineering 75, 145-149 (2014).

9. Qasim M Doos, Bashar Abdul Wahab, Int J. Mech. Eng. \& Rob, 1(3), 143-156 (2012). 